\title{
Can the Fast Bone Loss in Osteoporotic and Osteopenic Patients be Stopped with Active Vitamin D Metabolites?
}

\author{
M. A. Dambacher, ${ }^{1}$ M. Kranich, ${ }^{1}$ E. Schacht, ${ }^{2}$ M. Neff $^{3}$ \\ 'University Clinic Balgrist, Forchstrasse 340, CH-8008 Zurich, Switzerland \\ ${ }^{2}$ E. Tosse u. Co.MBH, Hamburg, Germany \\ ${ }^{3}$ Center for Osteoporosis, CH-8031 Zurich, Switzerland
}

\begin{abstract}
The aim of this study was to evaluate whether fast trabecular bone loss in osteoporotic and osteopenic patients can effectively be treated with active vitamin D metabolites. Thirty-one osteoporotic and osteopenic patients were monitored between 4 and 22 months before and between 8 and 18 months during the treatment. Fast bone losers were designated as osteoporotic or osteopenic patients with a loss of trabecular bone density in the radius of $3 \%$ or more calculated for 1 year. For this differentiation, the high precise peripheral quantitative computed tomography system (DENSISCAN 1000) was used (reproducability $0.3 \%$ in mixed collectives). The pretreatment loss and the "gain" under treatment with active vitamin D metabolites was calculated for 1 year. The treatment consisted of either $0.5 \mu \mathrm{g}$ calcitriol daily or $1 \mu \mathrm{g}$ of alfacalcidol daily. Before treatment, the trabecular bone loss in the radius/year was $-6.6 \pm 0.5 \%$ (mean \pm SEM). After treatment with vitamin D metabolites, the trabecular bone gain in the radius/year was $0.01 \pm 0.6 \%$ (mean $\pm \mathrm{SEM}$ ). The difference was highly significant $(P<0.001)$. In contrast to this, the loss of cortical bone density before treatment was $-1.8 \pm 0.3 \%$ (mean \pm SEM) and the reduced loss after treatment $-0.2 \pm 0.4 \%$ (mean \pm SEM), both values calculated for 1 year. This difference was less significant $(P<0.05)$. This study shows that the treatment with active vitamin $D$ metabolites is very effective in slowing fast trabecular bone loss in osteoporotic and osteopenic patients.
\end{abstract}

Key words: Fast bone loss - Osteoporosis - Quantitative computed tomography - Calcitriol - Alfacalcidol.

In postmenopausal and senile osteoporosis, reduced calcium absorption is often reported. Pathophysiologically, a disorder in the vitamin D metabolism as cause can be postulated, although it is of a different character. For both groups a lower concentration of $1,25(\mathrm{OH})_{2} \mathrm{D}_{3}$ in the serum, a decrease of the amount of $1,25(\mathrm{OH})_{2} \mathrm{D}_{3}$ receptors, and a disorder of the active calcium absorption in the intestine is known. For the postmenopausal osteoporosis there is a low parathyroid hormone (PTH) level and an additional deficit in the activation of the PTH-induced $1,25(\mathrm{OH})_{2} \mathrm{D}_{3}$ synthesis. For the senile osteoporosis, in addition to the above, there is a lack of vitamin D uptake and an increase in the

Correspondence to: $\mathrm{M}$. A. Dambacher amount of cells in the parathyroidea, with a higher level of PTH in the serum [1].

Vitamin D metabolites have proved to be effective in preventing osteoporosis by increasing low mineral density [2] and decreasing fracture rates [3-5] while showing a low toxicity; the incidence of hypercalcemia is $<1 \%$ [6]. The prevention of bone loss has been shown to be due to restoration to a positive calcium balance due to a correction of calcium malabsorption [7]. Furthermore, it has been reported that treatment with alfacalcidol improves the myopathy associated with the bone loss of aging [8] and should reduce the tendency to fall and the risk of osteoporotic fractures.

Until now anabolic substances like fluorides were used for the tailored treatment of osteoporosis in slow bone losers (loss of trabecular bone density in the radius of less than $3 \%$ calculated for 1 year). Fast bone losers were treated with antiresorptive agents like estrogens, calcitonin, and bisphosphonates [9]. The aim of the present study was to determine whether the treatment with the active vitamin D metabolites calcitriol and alfacalcidol can prevent a fast trabecular bone loss and could thus be considered as antiresorptive agents.

\section{Patient and Methods}

Treatment Protocol

Thirty-one postmenopausal female patients aged $47-82$ years were admitted to the study. The mean age was $68.1 \pm 8.9$ years. Patients with osteoporosis (trabecular bone density of the radius $\leqslant 2.5 \mathrm{SD}$ of the value of healthy 45-54-year-old normal women [10]) or osteopenia (trabecular bone density of the radius $1-2.5 \mathrm{SD}$ ) without treatment underwent a follow-up measurement with high precise peripheral quantitative computed tomography (pQCT) [11] not earlier than 4 months after the first measurement. If a trabecular bone loss in the radius of 3\% [12] (Fig. 1) or more, calculated for 1 year was found, the patients were defined as "fast losers" and admitted to the study. They underwent a treatment with active vitamin D metabolites for 8-18 months. The patients underwent a third pQCT measurement not earlier than 8 months after the treatment was started. The measured difference in percentage was again calculated for 1 year. Either $0.5 \mu \mathrm{g}$ calcitriol or $1 \mu \mathrm{g}$ alfacalcidol was given daily.

\section{Bone Densitometry}

The measurements were performed with the pQCT DENSISCAN 1000 (Scanco, Zürich, Switzerland) $[13,14]$, which has a reproducibility in mixed collectives of $0.3 \%$ [15]. The measuring procedure can be characterized as follows. The patient's arm is posi- 


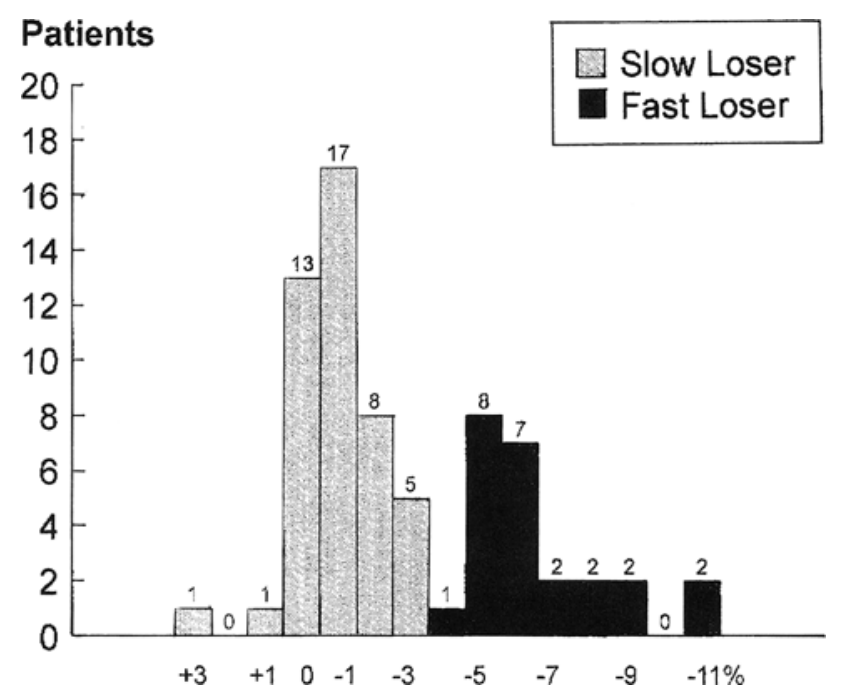

Fig. 1. Individual rate of trabecular bone loss in early postmenopausal women. The number of patients is plotted against the annual loss of trabecular bone density. The distribution was bimodal and shows a minimum at $3 \%$. This value is taken to separate fast bone losers from slow bone losers.

tioned in a radiolucent cast which enables comfortable immobilization during the measuring process and allows reproducible orientation of the bone axis relative to the measuring plane. The measuring system-a special-purpose CT instrument for low-dose bone densitometry-provides a digital radiogram as a positioning aid for the examination site. The examination site in the ultradistal radius is then converted with a stack of 10 tomograms (slice thickness $1 \mathrm{~mm}$, interslice distance $1.5 \mathrm{~mm}$ ), and the average bone density over core volume (D 50) is calculated. This value corresponds to the trabecular bone density $\left(\mathrm{mg} / \mathrm{cm}^{3}\right)$. After the three measurements, the bone volume common to all examinations of a patient is determined. Then the percentage of trabecular bone density changes in the radius are evaluated. The radiation dose per examination is only $0.1 \mathrm{mSv}$ [12]. Cortical bone density is measured in the diaphysis from six tomograms $(P<100)$.

\section{Statistical Analysis}

The mean and SEM were calculated for the changes in trabecular and cortical bone denisty in percentage between the first and the second as well as between the second and third pQCT. These changes before and after treatment were analyzed with the paired Student's $t$-test.

\section{Results}

Table 1 summarizes the measured initial values and changes in percentage of the trabecular bone density before and after treatment. Table 2 shows the same values for the cortical bone. The initial value found in the first pQCT for trabecular bone density in the distal radius for all patients was $133.61 \pm 11.86 \mathrm{mg} / \mathrm{cm}^{3}$ (mean $\pm \mathrm{SEM}$ ). This is clearly below the bone density of healthy women $45-54$ years old $\left(255 \mathrm{mg} / \mathrm{cm}^{3}\right.$ ).

After $10.13 \pm 0.87$ (mean \pm SEM) months, a second pQCT was performed which showed a trabecular bone loss
Table 1. Trabecular bone density of the radius: initial value and changes in percentage before and after treatment with active vitamin D metabolites calculated for 1 year

Initial value

$\left(\mathrm{mg} / \mathrm{cm}^{3}\right) \quad$ Percentage changes/year

\begin{tabular}{|c|c|c|c|}
\hline \multirow[b]{2}{*}{$133.6 \pm 11.9$} & \multicolumn{2}{|c|}{ Before treatment } & \multirow{2}{*}{$\frac{\text { After treatment }}{+0.01 \pm 0.6}$} \\
\hline & $-6.6 \pm 0.5$ & $P<0.001$ & \\
\hline
\end{tabular}

Table 2. Cortical bone density of the radius: initial value and changes in percentage before and after treatment with active vitamin D metabolites calculated for 1 year

Initial value

$\left(\mathrm{mg} / \mathrm{cm}^{3}\right) \quad$ Percentage changes/year

\begin{tabular}{llll}
\hline & \multicolumn{2}{l}{ Before treatment } & After treatment \\
\cline { 2 - 3 } $1101 \pm 37$ & $-1.8 \pm 0.3$ & $P<0.05$ & \\
\hline
\end{tabular}

$\mathrm{n}=31$

Values are mean \pm SEM

in the peripheral radius of $-6.61 \pm 0.52 \%$ (mean $\pm \mathrm{SEM}$ ) and the cortical bone loss of $-1.76 \pm 0.34 \%$ (mean \pm SEM) calculated for 1 year. After undergoing a treatment with either calcitriol or alfacalcidol for $12.13 \pm 0.43$ (mean \pm SEM) months, the third pQCT was performed. It showed a trabecular bone gain of $+0.01 \pm 0.59 \%$ (mean $\pm S E M)$ and a reduced loss of cortical bone of $-0.24 \pm 0.39 \%$ (mean \pm SEM) calculated for 1 year (Figs. 2 and 3). Analyzing the values before and after treatment with the paired Student's $t$-test, a highly significant difference for trabecular bone could be found $(P<0.001)$. For cortical bone, the difference was less significant $(P<0.05)$.

\section{Discussion}

The active vitamin $\mathrm{D}$ metabolites calcitriol $(0.5 \mu \mathrm{g} /$ daily $)$ and alfacalcidol ( $1 \mu \mathrm{g} /$ daily) have been found to be highly effective in the treatment of fast trabecular bone loss in osteoporotic and osteopenic patients. We have shown that this treatment did not only stop the loss of trabecular bone density in the peripheral radius measured with the high precise pQCT but there was a gain of density in several patients. The cortical bone density loss was at least significantly reduced. The radius as a nonweight-bearing bone is less sensitive to changes in mobility habits of the patient. The trabecular bone density of the radius seems to be the most reliable parameter for an osteoporosis follow-up because it reflects the bone turnover.

The therapy consisted of either $0.5 \mu \mathrm{g}$ of calcitriol daily, the active kidney metabolite of $1 \mu \mathrm{g}$ alfacalcidol daily. The $1 \alpha$-hydroxyvitamin $\mathrm{D}_{3}\left(1 \alpha-(\mathrm{OH}) \mathrm{D}_{3}\right)$ is a pro-drug which is hydroxylated in the liver and bone into the active 1.25 dihydroxyvitamin $D_{3}$ [3]. The dose of $0.5 \mu \mathrm{g}$ calcitriol is equivalent to $1 \mu \mathrm{g}$ alfacalcidol.

Vitamin D metabolites have been proven in this study to be antiresorptive, active agents in fast-losing osteoporosis. The mechanisms through which this occurs are reported to be (1) increasing the active vitamin $D$ metabolites in the 
before treatment after treatment

(1 $\mu g$ Alfacalcidol, $0.5 \mu g$ Calcitriol)

$\mathbf{p}<0.001$

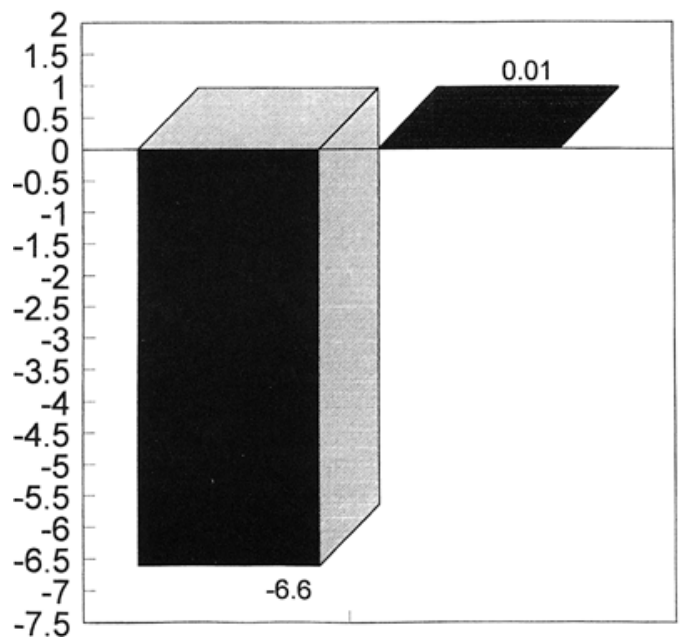

Fig. 2. Trabecular bone loss of the distal radius in percentages (calculated for 1 year) before and after treatment $(P<0.001)$.

before treatment after treatment

( $1 \mu g$ Alfacalcidol, $0.5 \mu g$ Calcitriol)

$p<0.05$

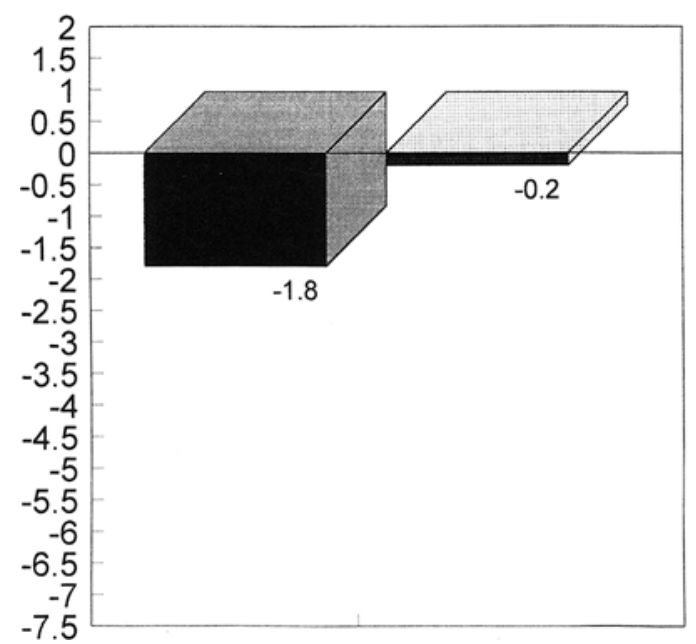

Fig. 3. Cortical bone loss of the radius in percentages (calculated for 1 year) before and after treatment $(P<0.05)$.

serum and the bone that are low due to a lower production in the kidney (lack of $1 \alpha$-hydroxylase) and the bone [16]; (2) facing the vitamin D resistance due to the lack of $1,25(\mathrm{OH})_{2} \mathrm{D}_{3}$ receptors in the intestine and the bone [17, 18]; (3) facing the effect of the senile secondary hyperparathyroidism [19] due to the increase of cell number in the parathyroid gland [20]; (4) reducing the increase of cytokines (IL-1, IL-6) induced by the postmenopausal estrogen deficiency [21,22]. In addition, the increase of PTH causes decreased coupled bone formation [23] which is due to changes of the insulin-like growth factor (IGF) system. PTH induces a higher production of binding protein 4 (IGFBP4) which neutralizes the anabolic effect of IGF.

Active vitamin D metabolites can replace the currently used antiresorptive agents such as estrogens, calcitonin, and bisphosphonates thanks to their high efficacy, low toxicity, and less side effects [24]. In the study's collective, no severe hypercalcemia was found; the highest measured value under treatment was $2.48 \mathrm{mmol} / \mathrm{liter}$ (upper normal value 2.42 $\mathrm{mmol} / \mathrm{liter}$ ). This is due to the controlled amount of oral calcium intake which is reported to be $600-800 \mathrm{mg}$ per day [25]. Moreover, a considerable number of our patients have reported an increase in general well-being and a decrease of pain. None of the patients suffered severe dizziness. Only a few patients have reported intestinal problems such as stomach pain or diarrhea. These problems could always be solved by interrupting the treatment for about 2 weeks and restarting it in splitted dose of, e.g., two times $0.25 \mu \mathrm{g}$ calcitriol $2 \times /$ day.

\section{References}

1. Dambacher MA, Schacht E (1996) Osteoporosis and active vitamin D metabolites: the shape of things to come. EularPublishers, Basle

2. Aloia JF, Vaswani A, Yeh JK, Ellis K, Yasumura S, Cohn SH (1988) Calcitriol in the treatment of postmenopausal osteoporosis. Am J Med 84:401-408

3. Orimo $\mathrm{H}$ (1994) Clinical application of $1 \alpha(\mathrm{OH}) \mathrm{D}_{3}$ in Japan. Aktuel Rheumatol 19(suppl):27-30

4. Gallagher JC, Riggs BL (1990) Action of 1,25-dihydroxyvitamin $\mathrm{D}_{3}$ on calcium balance and bone turnover and its effect on vertebral fracture rate. Metabolism 39(4)(suppl 1): 30-34

5. Tilyard MW, Spears GF, Thomson J, Dovey S (1992) Treatment of postmenopausal osteoporosis with calcitriol or calcium. N Engl J Med 326(6):357-362

6. Gallagher JC (1994) Vitamin D metabolism and therapy of osteoporosis. Aktuel Rheumatol 19(supp):31-34

7. Francis RM, Peacock M (1987) Local action of oral 1,25dihydroxycholecalciferol on calcium absorption in osteoporosis. Am J Clin Nutr 46:315-318

8. Sørensen OH, Lund BI, Saltin B, Lund BJ, Andersen RB, Hjorth L, Melsen F, Mosekilde L (1979) Myopathy in bone loss of ageing: improvement by treatment with $1 \alpha$-hydroxycholecalciferol and calcium. Clin Sci 56:157-161

9. Dambacher MA (1996) Osteoclasts inhibitory agents. In: Bröll H, Dambacher MA (eds) Osteoporosis: a guide to diagnosis and treatment. Karger, Basle, pp 169-220

10. WHO (1994) Assessment of osteoporotic fracture risk and its role in screening for postmenopausal osteoporosis. WHO Technical Report Series, Geneva

11. Gass R, Neff M (1995) Osteoporoseprävention, eingeleitet mit peripherer quantitativer Computertomographie: Dünnschichtund Mehrschichttechnik. Schweiz Rundsch Med 84(18):521525

12. Rüegsegger $P$ (1994) The use of peripheral QCT in the evaluation of bone remodelling. Endocrinologist 4(3):167-176

13. Rüegsegger P (1990) Bone density measurement. In: Bröll H, Dambacher MA (eds) Osteoporosis: a guide to diagnosis and treatment. Karger, Basle, pp 103-117

14. Dambacher MA (1996) Practical problems of today. A personal view. In: Bröll H, Dambacher MA (eds) Osteoporosis: a guide to diagnosis and treatment. Karger, Basle, pp 278-284

15. Reeve J, Kröger H, Nijs J, Pearson J, Felsenberg D, Reiners C, Schneider P, Mitchell A, Rüegsegger P, Zander C, Fischer M, Bright J, Henley M, Lunt M, Dequeker J (1993) Radial cortical and trabecular bone densities of men and women stan- 
dardized with the European Forearm Phantom. Calcif Tissue Int 58:135-143

16. Lidor C, Sagiv P, Amdur B, Gepstein R, Otremski I, Hallel T, Edelstein $S$ (1993) Decrease in bone levels of 1,25-dihydroxyvitamin D in women with subcapital fracture of the femur. Calcif Tissue Int 52:146-148

17. Horst RL, Goff JP, Reinhardt TA (1990) Advancing age results in reduction of intestinal and bone 1,25-dihydroxyvitamin D receptors. Endocrinology 126(2):1053-1057

18. Ebeling PR, Sandgren ME, DiMagno EP, Lane AW, DeLuca HF, Riggs BL (1992) Evidence of an age-related decrease in intestinal responsiveness to vitamin $D$ : relationship between serum 1,25 -dihydroxyvitamin $\mathrm{D}_{3}$ and intestinal vitamin $\mathrm{D}$ receptor concentration in normal women. J Clin Endocrinol Metab 75(1):176-182

19. Fujisawa Y, Kida K, Matsuda H (1984) Role of change in vitamin $\mathrm{D}$ metabolism with age in calcium and phosphorus metabolism in normal human subjects. J Clin Endocrinol Metab 59(4):719-726

20. Ledger GA, Burrit MF, Kao PC, O'Fallon WM, Riggs BL,
Khosla S (1994) Abnormalities of parathyroid hormone secretion in elderly women that are reversible by short-term therapy with 1,25-dihydroxyvitamin $\mathrm{D}_{3}$. J Clin Endocrinol Metab 79(1):211-216

21. Manolagas SC, Hustmyer FG, Yy XP (1990) Immunomodulating properties of 1,25 dihydroxyvitamin $D_{3}$. Kidney Int 38(suppl 29):9-16

22. Muller K, Diamant M, Bendtzen K (1990) Inhibition of production and function of interleukin 6 by 1,25-dihydroxyvitamin $\mathrm{D}_{3}$. Immunol Lett 28:115-120

23. Baylink DJ, Libanati CR (1994) The actions and therapeutic applications of $1 \alpha$-hydroxylated derivates of vitamin $\mathrm{D}$. Aktuel Rheumatol 19(suppl):10-18

24. Gallagher JC (1993) Prevention of bone loss in postmenopausal and senile osteoporosis with vitamin D analogues. Osteoporosis Int 3(suppl 1):S172-175

25. Pouilles JM, Trémollières F, Ribot C (1992) Prevention of post-menopausal bone loss with $1 \alpha$-hydroxy vitamin $D_{3}$. A three-year prospective study. Clin Rheumatol 11(4):492-497 